\title{
BUILDING INFORMATION MODELLING FOR CULTURAL HERITAGE: A REVIEW
}

\author{
S. Logothetis, A. Delinasiou, E. Stylianidis
}

Aristotle University of Thessaloniki, Faculty of Engineering, School of Spatial Planning \& Development, Thessaloniki, Greece, slogothet@auth.gr, adelinas@auth.gr, sstyl@auth.gr

$25^{\text {th }}$ International CIPA Symposium

KEY WORDS: Building Information Modelling, BIM platforms, HBIM, cultural heritage documentation, 3D environments

\begin{abstract}
:
We discuss the evolution and state-of-the-art of the use of Building Information Modelling (BIM) in the field of culture heritage documentation. BIM is a hot theme involving different characteristics including principles, technology, even privacy rights for the cultural heritage objects. Modern documentation needs identified the potential of BIM in the recent years. Many architects, archaeologists, conservationists, engineers regard BIM as a disruptive force, changing the way professionals can document and manage a cultural heritage structure. The latest years, there are many developments in the BIM field while the developed technology and methods challenged the cultural heritage community in the documentation framework. In this review article, following a brief historic background for the BIM, we review the recent developments focusing in the cultural heritage documentation perspective.
\end{abstract}

\section{INTRODUCTION}

BIM has been a growing development within the past decade in the field of cultural heritage documentation, paving the way towards a future in the virtually built environment. Many architects, archaeologists, conservationists, engineers regard $\mathrm{BIM}$ as a disruptive force, changing the way professionals can document and manage a historical monument. A monument is a type of structure that was created to commemorate an important event or a person. This event maybe has become important to a social group as a part of their cultural heritage or as an example of the historic architecture. The term "monument" is often applied to structures or buildings that are considered examples of important architectural and cultural heritage.

\subsection{Literature Review}

The term BIM was first used by Phil Bernstein from Autodesk. Another theory supports that Professor Charles Eastman extensively used the term in his books in late 1970. Later, the term was applied by German Jerry Laiserin to represent the manufacturing process and to facilitate the exchange of information in digital form. The first implementation of BIM was under the Virtual Building concept in 1987 by the company Graphisoft with platform ArchiCAD.

Despite the trend of scientific community to adopt the BIM technology for the design and life-cycle management of constructions, little research has been undertaken to explore the value of BIM in the management and documentation of cultural heritage monuments (Fai et al., 2011).

However, researchers have recently developed different techniques for the reliable and coherent management of information related to cultural heritage (Saygi and Remondino, 2013). The first usage of the BIM for existing buildings was in research of Arayici in 2008. That advocates the adoption of BIM in order to move beyond rote 3D visualization through the incorporation of intelligent, multifunction and multi representational data. The research focuses on adapting automated data processing and pattern recognition that leverages $3 \mathrm{D}$ point cloud data towards the generation of a simple building envelope (Fai et al., 2011).

Furthermore, in two researches (Murphy et al., 2009 \& 2011), they developed the Historic Building Information Modelling (HBIM) for the integration of contemporary technology and BIM approach in the field of cultural heritage documentation. It functions as plug-in for BIM and it is a novel prototype library of parametric objects built from historic data and a system for mapping the parametric objects onto a point cloud and image survey data.

This review paper consists of four sections relating to the trends in BIM technology in cultural heritage documentation. The first section briefly follows a history of the BIM development as used in the documentation of cultural heritage, in order to obtain a 3D representation of a monument in the form of a structured hierarchical set of structural elements (such as walls, vaults, roof, decorative elements etc.). The second section contains a summary of current available BIM software (commercial and open source) that are provided. In addition, descriptions are provided for each platform in order to determine have a comparative analysis among the various software. The third section describes the recent BIM applications in world monuments in order to facilitate the documentation of the cultural heritage. The final section concludes with a brief explanation of future BIM uses, developments and trends in documentation of cultural heritage.

\section{BUILDING INFORMATION MODELLING}

BIM is primarily a $3 \mathrm{D}$ digital representation of an environment, a structure or a building with its intrinsic characteristics. It consists of intelligent building components 
or characteristics of environments which includes data attributes and parametric rules for each object (Hergunsel, 2011). According to the National BIM Standard-United State Project Committees (NBIMS-US), BIM is " $a$ digital representation of physical and functional characteristics of a facility and a shared knowledge resource for information about a facility forming a reliable basis for decisions during its life-cycle; defined as existing from earliest conception to demolition" (Saeed, 2013).

What we observe, when comparing the two, is that the BIM tend to be a completely different system from Computer Aided Design (CAD), due to the fact that the procedures have now turned into an almost internalised system to integrated information, when at the same time CAD gets the information needed through external sources. It is noted that "a BIM model contains the buildings actual constructions and assemblies rather than a two-dimensional representation of the building that is commonly found in CAD-based drawings" (Krygiel and Nies, 2008). The BIM technology provides a number of advantages over CAD by being able to manage information, not just graphics. Also is supporting a controlled environment which in most commonly miscommunication eliminates the data redundancy (Bynum, 2010).

Many are the basic capabilities of BIM, with the most important of them aiming to: develop the strategy of building project design, construction and maintenance management; ensure integration management of graphical and informational data flows, combine the graphical interface with the information flows and process descriptions; transform individual executors into teams and decentralise tools into complex solutions, this leading to individual tasks being implemented as complex processes; perform life cycle operations of a construction project more effective, faster and with lower cost (Popov et al., 2008).

\subsection{The technology}

BIM technology can realise a $3 \mathrm{D}$ virtual model of the construction to be realised or illustrate an existing model. The model becomes absolutely comprehensible from all individuals that participate in its construction while at the same time provides the possibility of important utilities during building life-cycle (Brumana et al., 2013).

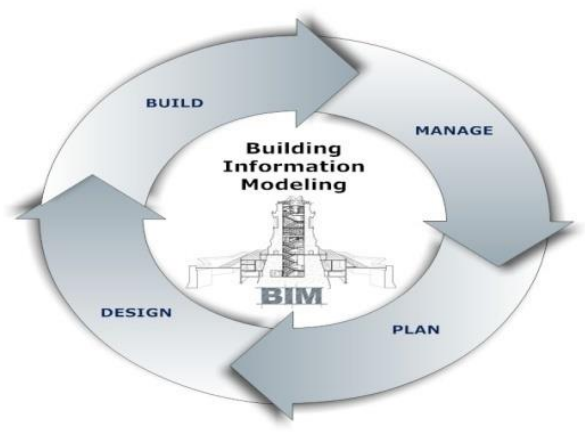

Figure 1: BIM Model

The systems which are using BIM technology differ from the 3D CAD because are "smarter" and can present the information more detailed; contained information and data for the whole 'construction project' such as: drawings, structural elements, mechanical systems, materials' measurements, data suppliers, scheduling and financial data.

BIM starts from the initial design and during the construction phase is used as a source of information. All information is incorporated in a model and thus can be studied securing valuable time and cost benefits.

The BIM technology contributes to the creation of a digital representation having all physical and functional building characteristics in five dimensions (5D). These are the three (3D) primary spatial dimensions (width, height and depth), the fourth dimension (4D) is time and the fifth (5D) is cost. The developed virtual model provides an accurate overall picture to the project team (architects, civil engineers, surveyors, mechanical engineers, contractors, conservators, etc.) (Figure 1). One of the most important BIM's characteristics is the provision of a reliable basis for timely and quick decisions, helping the involved personnel to increase quality and productivity in the design but also during project operation. Since, BIM has greatly evolved in the recent years by providing high quality information, the technology help to significantly reduce defects and risks in all stages of a project.

\subsection{The BIM components}

A BIM is based on components, namely parametric objects that are stored in object libraries. In fact, these are software counterparts of the real objects used to construct the physical building, such as steel beams, concrete slabs, framing, drywall, ducts, windows, etc. The components are represented in 3Dmodes while additional information is stored so as to give make them "intelligent".

The BIM components contain geometric information, associated with data and rules. These have a non-redundant geometry while they have parametric rules that automatically change associated geometries when inserted into a model or when changes are made to associated objects. The components' rules are crucial since they can identify when a particular modification violates object feasibility. The BIM components have the ability to link or export sets of attributes such as structural materials, acoustic data, energy data, cost, etc., to other applications and models (Eastman et al., 2008).

The amount of the model detail is defined by more parameters beside width, depth and height. Additional parameters can be defined such as weight, density, cost, etc. to give added value to the model used. This reflects when the building is virtually constructed as it is enriched of thoroughly defined, intelligent objects. These objects now are incorporate intelligence; i.e. where they belong, how they are connected with other objects, what are they comprise from, etc.

In modern BIM platforms, we can undoubtedly create and manage parametric geometries, analysing them in primitives that can be connected through hierarchical relationships. This is a perfect procedure when creating simple objects from software libraries, where constraints and shapes were already set. However, it is much more difficult when components are generated to represent heterogeneous and original existing morphologies (e.g. data using digital photogrammetry or laser scanning). In this case, BIM designs have to be mostly remodelled manually, since automatic feature recognition in 
available with commercial AEC (Architecture, Engineering, Construction) computer programs are still not effective (Garagnani et al., 2013).

In the case of cultural heritage objects things are more complex as cultural heritage monuments are mainly made of components and materials whose geometry and characteristics are not representative for typical software libraries. A possible solution to the lack of geometric primitives issue in the current typical BIM software libraries, involves the so called HBIM approach. In HBIM the parametric objects are built from historic data (surveys, assays and literature) and layered in plug-in libraries aimed to map the elements onto point clouds data and image survey data (Dore and Murphy, 2012). Unfortunately, this methodology assumes buildings to be documented through correctly organised components, are already presented in libraries, with limited capabilities to change them in order to represent possible existing different states (Garagnani et al., 2013).

\begin{tabular}{|c|c|c|c|c|}
\hline Product Name & Manufacturer & BIM Use & Primary Function & Supplier Web Link \\
\hline Revit Architecture & Autodesk & $\begin{array}{l}\text { Creating and reviewing } \\
\text { 3D models }\end{array}$ & $\begin{array}{l}\text { Architectural Modelling } \\
\text { and parametric design. }\end{array}$ & $\underline{\text { www.autodesk.com }}$ \\
\hline Bentley Architecture & Bentley Systems & $\begin{array}{l}\text { Creating and reviewing } \\
\text { 3D models }\end{array}$ & Architectural Modelling & $\underline{\text { www.bentley.com }}$ \\
\hline SketchUpPro & Google & $\begin{array}{l}\text { Conceptual 3D } \\
\text { Modelling }\end{array}$ & $\begin{array}{l}\text { Conceptual Design } \\
\text { Modelling }\end{array}$ & $\underline{\text { www.sketchup.google.com }}$ \\
\hline ArchiCAD & Graphisoft & $\begin{array}{l}\text { Conceptual 3D } \\
\text { Architectural Model }\end{array}$ & $\begin{array}{l}\text { Architectural Model } \\
\text { Creation }\end{array}$ & www.graphisoft.com \\
\hline TeklaStructures & Tekla & $\begin{array}{l}\text { Conceptual 3D } \\
\text { Modelling }\end{array}$ & $\begin{array}{l}\text { Architectural 3D Model } \\
\text { Application }\end{array}$ & $\underline{\text { www.tekla.com }}$ \\
\hline DProfiler & Beck Technology & $\begin{array}{l}\text { Conceptual Design and } \\
\text { Cost Estimation }\end{array}$ & $\begin{array}{l}\text { 3D conceptual modelling } \\
\text { with real-time cost } \\
\text { estimating }\end{array}$ & $\underline{\text { www.beck-technology.com }}$ \\
\hline Vectorworks Designer & Nemetschek & $\begin{array}{l}\text { Conceptual 3D } \\
\text { Modelling }\end{array}$ & $\begin{array}{l}\text { Architectural Model } \\
\text { Creation }\end{array}$ & www.nemetschek.net \\
\hline Affinity & Trelligence & $\begin{array}{l}\text { Conceptual 3D } \\
\text { Modelling }\end{array}$ & $\begin{array}{l}\text { A 3D Model Application } \\
\text { for early concept design }\end{array}$ & $\underline{\text { www.trelligence.com }}$ \\
\hline Edificius & AccaSoftware & $\begin{array}{l}\text { Architectural BIM Design } \\
\text { and 3D object CAD }\end{array}$ & Architectural Modelling & $\underline{\text { www.accasoftware.com }}$ \\
\hline Vico Office & Vico Software & $\begin{array}{l}\text { Conceptual 5D } \\
\text { Modelling }\end{array}$ & $\begin{array}{l}\text { 5D conceptual model } \\
\text { generate cost and } \\
\text { schedule data }\end{array}$ & www.vicosoftware.com \\
\hline Revit Structure & Autodesk & Structural & $\begin{array}{l}\text { Structural Modelling and } \\
\text { parametric design }\end{array}$ & $\underline{\text { www.autodesk.com }}$ \\
\hline $\mathrm{SDS} / 2$ & Design Data & Structural & $\begin{array}{l}\text { 3D Structural Modelling } \\
\text { and Detailing }\end{array}$ & www.dsndata.com \\
\hline RISA & $\begin{array}{l}\text { RISA } \\
\text { Technologies }\end{array}$ & Structural & $\begin{array}{l}\text { Full Suite of Structural } \\
\text { Design Applications }\end{array}$ & www.risatech.com \\
\hline Robot & Autodesk & Structural Analysis & $\begin{array}{l}\text { Bi-directional link with } \\
\text { Autodesk Revit Structure }\end{array}$ & www.autodesk.com \\
\hline Green Building Studio & Autodesk & Energy Analysis & $\begin{array}{l}\text { Measure energy use and } \\
\text { carbon footprint }\end{array}$ & $\underline{\text { www.autodesk.com }}$ \\
\hline Ecotect & Autodesk & Energy Analysis & $\begin{array}{l}\text { Weather, energy, water, } \\
\text { carbon emission analysis }\end{array}$ & $\underline{\text { www.autodesk.com }}$ \\
\hline $\begin{array}{l}\text { Structural Analysis } \\
\text { Design Detailing, } \\
\text { Building Performance }\end{array}$ & Bentley Systems & $\begin{array}{l}\text { Structural } \\
\text { Analysis/Detailing, } \\
\text { Quantity Take-off, } \\
\text { Building Performance }\end{array}$ & $\begin{array}{l}\text { Measure, assess and } \\
\text { report building } \\
\text { performance. }\end{array}$ & www.bentley.com \\
\hline Solibri Model Checker & Solibri & $\begin{array}{l}\text { Model Checking \& } \\
\text { Validation }\end{array}$ & $\begin{array}{l}\text { Rules-based checking for } \\
\text { compliance and } \\
\text { validation of all objects } \\
\text { in the model }\end{array}$ & $\underline{\text { www.solibri.com }}$ \\
\hline TeklaBIMSight & Tekla & Model Viewer & $\begin{array}{l}\text { Combine models, check } \\
\text { for clashes and share } \\
\text { information }\end{array}$ & $\underline{\text { www.teklabimsight.com }}$ \\
\hline xBIMXplorer & Open BIM & IFC viewer & $\begin{array}{l}\text { Open, view IFC files and } \\
\text { navigate through a model }\end{array}$ & http://xbim.codeplex.com \\
\hline Solibri Model Viewer & Solibri & Model Viewer & $\begin{array}{l}\text { Open all Standard IFC } \\
\text { Solibri Checker Files }\end{array}$ & $\underline{\text { www.solibri.com }}$ \\
\hline Navisworks Freedom & Autodesk & 3D Model Viewer & $\begin{array}{l}\text { Open, view IFC files and } \\
\text { navigate through a model }\end{array}$ & www.autodesk.com \\
\hline
\end{tabular}

Table 1. Commercial and open source BIM tools 


\section{EXISTING BIM PLATFORMS}

The current BIM platforms are
separated in three distinctly different sets of tools:
$\begin{aligned} & \text { 1. } \text { tools for design 3D models (3D modellers); } \\ & 2 . \text { tools of projection / visualisation models } \\ & \text { (Viewers/Surface modellers) and } \\ & \text { 3. } \text { tools of calculating analysis of models (Analysers), } \\ & \text { (see http://www.awci.org/pdf/bim.pdf) }\end{aligned}$

There are several major software developers that supply products with functionality in the BIM world, separated in commercial platforms and open source platforms. The 3D modeller is the real BIM tool, working with solid, parametric objects in sufficient features to virtually construct the building. In order to realise how the building will "look", a surface modeller or a viewer to which all shapes are empty is necessary. Analysers are normally third-party software that communicate to the main BIM tool, e.g. analyse data from the 3D modeller to determine the model's energy efficiency or day lighting (see http://www.awci.org/pdf/bim.pdf).

The commercial and open source software presented in the following sections is perhaps the most well-known BIM exist nowadays. There are many more equally important software and some of them are presented in Table 1.

\subsection{Commercial platforms}

There are plenty BIM tools used for cultural heritage.The most popular commercial software are GraphiSoft ArchiCAD, Autodesk Revit, Bentley MicroStation V8i and Tekla Structures.

ArchiCAD (Graphisoft) is an architectural design platform, created around the BIM concept as standalone software. The modelling of the objects in ArchiCAD can be achieved through using standard parametric of structure elements. The elements created as new objects using the embedded scripting language Geometric Description Language (GDL) or imported from the software (such as walls, roofs, beams, slabs, etc.). The use of GDL allows the creation of any number of rich parametric BIM objects and for their storage in internal libraries or databases for further reuse or modification (Murphy et al., 2011).

Revit Autodesk is also BIM software that gives the possibility to the user to create a mass model with a combination of void and solid forms. The faces of the mass volume can be converted into building elements and floors and other architectural elements can be generated inside the mass model (Boeykens et al., 2008). Autodesk expanded this BIM platform and created three Revit products: Architecture, Structure and MEP. Revit is one of many varieties of BIM software which support the open XML-based IFC standard, developed by the BuildingSMART organisation. This file type makes it possible for a client or general contractor to require BIM-based workflow from the different discipline consultants of a building project.

Bentley Systems offers a wide range of related products for architecture, construction and engineering. The architectural BIM platform, Bentley Architecture that presented in 2004 is an evolution of software Triforma. The latest software is the MicroStation V8i that used for the AEC (Architecture, Engineering, and Construction). Also, additional operations of all infrastructure types including buildings, roads, bridges, utility systems, railway lines, communication networks, wastewater networks, water, process plants, mining etc. The MicroStation can be used either as a software application or as a technology platform.

The platform provides immersive interaction with 2D drawings and 3D models, to produce trusted deliverables such as 3D plots, information-rich 3D PDFs and precise designs. The analysis capabilities and data enable performance simulation of designs, including animations and lifelike renderings. Furthermore, the ability to integrate a comprehensive breadth and depth of engineering geometry and data from an unmatched range of CAD software and engineering formats ensures that users can work seamlessly with the entire project team.

The MicroStation is used as technology platform for specific applications. Bentley and other software vendors use such technology platforms. It offers subsystems for consistent integration of data, geometry and increasing the user experience across a broad portfolio of comprehensive engineering, design and simulation applications. The platform ensures and leverages for each application the advantages, enabling in multidisciplinary groups to benefit from an interoperable software portfolio (Bentley, 2015).

Tekla Structures is a BIM software that enables the creation and management of accurately detailed and highly constructible 3D models irrespective of material or complexity of the structure. Tekla models can be used to cover the whole building process from conceptual design to construction and the management of the structure. The software can be used to interface with other existing applications, or as a platform to develop an internal customizable solution. It is an open solution that supports standardisation and interoperability.

The software supports interfaces with: DWG, IFC, DGN, DXF, CIS/2, DTSV and SDNF file formats. Tekla Structures has the ability to model structures that incorporate all kinds of structural materials and detailing; its ability to support very large models and concurrent operations on the same project and with multiple simultaneous users. It supports compilation of complex parametric custom component libraries with little or no programming (Eastman et al., 2008).

\subsection{Open source platforms}

Many software companies have developed several commercial platforms for BIM. In the field of open source platforms we observe an inadequate collection of tools. Most of them belong to the category of tools for projection and visualisation models.

Edificius (Acca Software) is an advanced design tool for BIM. Professionals can obtain: section views, elevation views, floor plan views, tables, reports, construction details, schedules, perspective views, isometric views, renderings, animations and photo inserts.

This software allows the use with custom working drawing layouts and import/export in standard formats such as DXF/DWG for CAD drawings, OBJ and 3DS for 3D models, BMP and JPG for renders. Projects and professional collaborations are possible to be shared with every designer; all data is saved in a single file that anyone can open and work with the Edificius Free UPP. Edificius Free UPP increases the BIM potential by integrating the features of other software: 
- $\quad$ PriMus for bills of quantities

- $\quad$ SketchUp for solid modelling

- Edificius-CAD for DWG CAD drawings

- EdiLus for structural calculations

Tekla BIMsight is a BIM software application based on construction project collaboration. The entire workflow can combine the models, control the clashes, and share the information using the same easy to use BIM platform. The Tekla BIMsight enables project participants to identify and solve issues already in the design phase before the final visualisation.

Autodesk Navisworks Freedom software is a free viewer for NWD and DWF file formats. The use of Navisworks Freedom extends the whole-project view to all stakeholders, helping to improve the collaboration and communication. With such software it is possible to create multi-disciplinary models in a wide range of applications, including information from BIM, digital prototypes and process plant design. All ofthese can be combined into a single integrated project model and published into the NWD format. The published file provides access to: object properties, model hierarchy and embedded review data, including animations, viewpoints and comments.

\section{BIM FOR CULTURAL HERITAGE}

The plug-in HBIM is a library of parametric objects that created from historic data. Furthermore, it is a system for mapping the parametric objects onto a point cloud and the survey image data. The HBIM process is started with distant collection of survey data using terrestrial laser scanning or digital photogrammetric modelling.

In building parametric objects, the problem of file format and exchange of data has been overcome by using Geometric Description Language (GDL). The scripting in GDL allows for sharing and editing of the parametric objects at different levels (Murphy et al., 2012).

The use of historic data introduces the opportunity to develop detail behind the object's surface concerning its methods of construction and material composition. In the last stage of the HBIM process, the libraries of parametric objects are mapped onto the point cloud and image survey data using a platform of cross software management. Full engineering orthographic drawings and 3D models can be automatically produced from the HBIM (Murphy et al., 2011).

In addition, benefits of generating heritage structures in a 3D BIM environment:

- Remote reviewing of the building exterior and interior.

- Allows study with new structures in the environment context.

- Possibility to survey of different periods of time.

- Better estimation of the structure using images to understand texture, massing and form.

- Allows appreciation of renovations and adaptations prior to committing to a strategy and full construction documents.

- Most people can understand a 3D building more than a 2D flat drawing (Maddigan, 2012).

\subsection{BIM applications in the cultural heritage context}

There are different BIM applications in the cultural heritage context and this section describes characteristic cases. One of them is the Basilica of St. Maria of Collemaggio in L'Aquila of Italy that was damaged by the earthquake in 2009. In this survey created a 3D detailed model (Figure 2) to support the on-going design project of conservation and intervention of the damaged temple parts. The HBIM model manages the stages of simulation of structural behaviour, analysis, economic evaluation of the project, and restoration of the temple (Oreni et al., 2014).

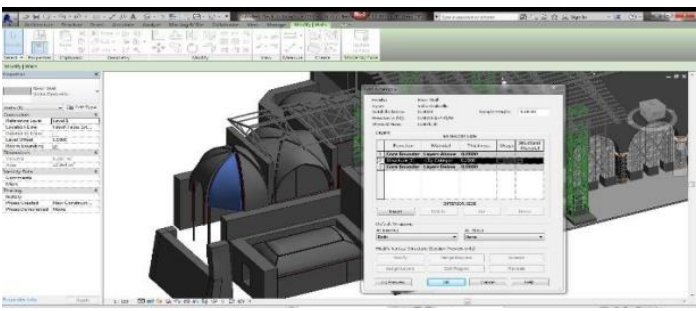

Figure 2.3D CRevit model of the Basilica St. Maria and WBS to manage the restoration (Oreni et al., 2014)

Another BIM application is the modelling of the Henrietta Street, in Dublin, of Ireland. The process started with laser scanning and the final orthographic images was imported into the BIM platform ArchiCAD. The use of laser scanning and photogrammetry can record very high and accurate levels of detail in the field for cultural heritage. Next, the modelling was completed by combining all the required library parts included in the HBIM plug-in. The final stage is converting the HBIM model (Figure 3) for Henrietta Street into CityGML for further GIS analysis. For this purpose Google SketchUp with the CityGML plug-in was used. Finally, the integration to CityGML can provide further capabilities for linking the information systems with $3 \mathrm{D}$ heritage model. The CityGML model can be integrated into GIS systems for analysis and efficient management that is required for maintaining important heritage monuments (Dore and Murphy, 2012).

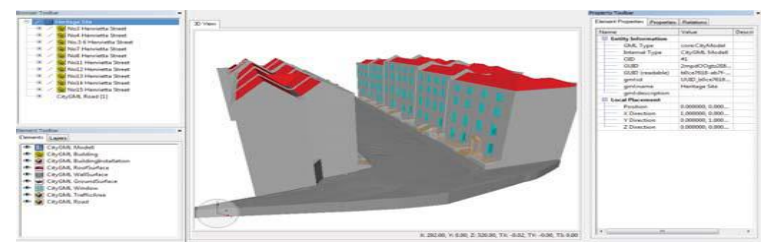

Figure 3. Final HBIM Model of the Henrietta Street (Dore et al., 2012)

Another project describes the Batawa project-model that is a redevelopment proposal for approximately 600 hectares of land that includes a former factory in Toronto (a cluster of three 19th century heritage buildings) with its rich history of modern architecture and town planning. The purpose is to document the heritage assets of Batawa and to develop a BIM model using available software packages that are appropriate for specific applications (AutoCAD, Civil 3D, SketchUp, Revit,). That will serve as a digital archive to help in conserving the extant heritage buildings and planning and to test future development proposals within the context of these historic buildings and plans (Fai et al., 2011). 
The Batawa project brings together heterogeneous datasets into a single digital object that allows access to, and on-going verification of the individual assets that comprise the integrated model. This includes data related to the type of the building, performance and construction, as well as material typically associated with intangible heritage such as storytelling and music. The model uses point cloud data acquired through terrestrial laser scanning. In order to bring all the pieces together into a single model Navisworks used, a robust project management tool that is able to integrate the diverse software required for the project (Fai et al., 2011).

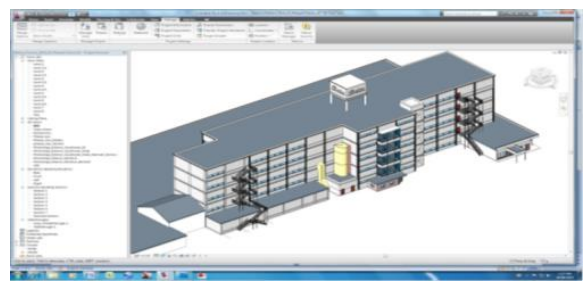

Figure 4. Final HBIM Model of factory (Fai et al., 2011)

The 3D environment (Figure 4) was created to allow the navigation for maintaining the BIM intelligence of the objects that comprise the model. This way we can examine the model at both micro and macro scales with no loss of reliability or data. Then, intangible heritage information was incorporated such as historical images and texts, multilanguage storytelling, and music. Finally, the Batawa Model can be viewed trans-temporally by employing the timeline function of the project management software (Fai et al., 2011).

One more case describes the procedures for the visualisation of Sant' Apollinare Nuovo in Ravenna of Italy: the Byzantine church with walls covered with mosaics. For the monument's modelling, the data were acquired using a Leica ScanStation C5 laser scanner which where integrated with the dense point surfaces obtained through digital photogrammetry, using Menci Z-Scan software. The final result was a model (Figure 5) of the inner nave, including some details captured with a higher number of points: point clouds were superimposed in order to get a complete documentation of the walls and mosaics. The point clouds were registered, decimated and processed in order to be transformed in a proper geometric input for Autodesk Revit Architecture 2012. A simple plug-in for Revit, the GreenSpider, was used to layout points in space as if they were nodes of an ideal cobweb. The parametric production of smart elements is easier and much more accurate. This application is able to translate points into native reference snaps aimed to allow elements modelling with much more precision instead of a simple tracing out (Garagnani and Manfredini, 2013).

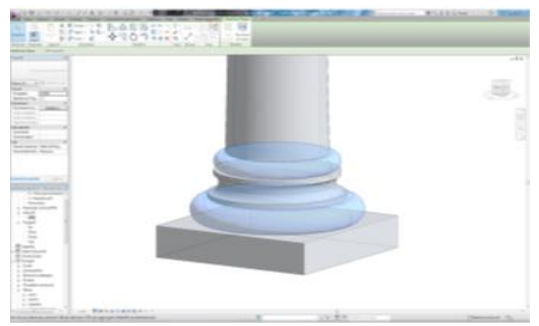

Figure 5. Final HBIM Model of pillar (Garagnani and Manfredini, 2013)
The last example refers to the valuation and dissemination of the role of the Church of Santa Maria at Scaria in Como of Italy. The study attempted to explain the reconstruction and the main transformations and chronological phases of the church, from the Romanic to the Baroque interventions and to the more recent ones. For this purpose, laser scanning and photogrammetric surveys have been carried out with on-site stratigraphic analysis while available historical documents have used as well. An integrated BIM approach (Figure 6, with Autodesk Revit 2013) has been chosen as an experimental way of transmitting a piece of the church's life history to the local people and also for touristic purposes. The aim of the research was also to designate the potential BIM platform when used for energy analysis with the appropriate tools for life-cycle building management and energy efficiency. Finally, the research applied the Building Performance Analysis with collaboration of BIM platform and Autodesk's web-based energy analysis software the Green Building Studio (Brumana et al., 2013).

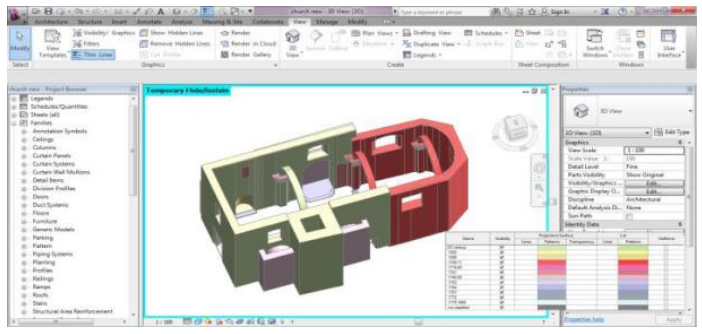

Figure 6. HBIM Model of the church St. Maria di Scaria, with stratigraphic information related to each singular object (Brumana et al., 2013)

\section{CONCLUSIONS AND DISCUSSION}

The paper presents a review of the BIM use in the field of cultural heritage documentation. The diversity and complexity of BIM technology is obvious in many different fields; environment, buildings, construction, monument, structure framework.

We report the existing BIM platforms. On one hand the most popular commercial software for HBIM which are quite many while they are expensive enough and inaccessible for researchers and SMEs. On the other hand, in the field of open source no outstanding platforms for HBIM exist. In practice, there are some model viewers; however, there is only one complete BIM platform.

In addition, we reported five (5) of the most representatives BIM applications in the area of cultural heritage, the majority of them from Italy.

The review of the current BIM applications illustrates that most researchers adopt a particular methodology for developing a HBIM for historic environments and structures. In practice, this process starts with data collection and data processing, e.g. laser data and images; identify the structural details from historic and architectural books; create the database of parametric historic objects; correlation of parametric objects onto laser data and final the production of the survey drawings for the 3D historic virtual model. In this detailed 3D model more details can be included about the various objects such as construction materials, schedules for cost decay, energy etc. adding intelligent data to the point cloud. 
This review showed that many developments occurred the last year in the area of BIM while the potential for many more exist. There is a still lot of space for more and more developments. In the area of open source platforms it seems that many more could be done to moderate the high prices in the existing commercial platforms.

\section{REFERENCES}

Arayici, Y., 2008. Towards Building Information Modelling for Existing Structures, Structural Survey, 26.3, 210-222.

Bentley MicroStation, 2015. http://www.bentley.com/enUS/Products/microstation+product+line/, (20-02-15).

Boeykens, S. and H. Neuckermans. 2008. "Scale Level and Design Phase Transitions in a Digital Building Model." http://www.asro.kuleuven.be/IDEA.

Brumana R., Oreni D., Raimondi A., Georgopoulos A., Bregianni A., 2013. From survey to HBIM for documentation, dissemination and management of built heritage. Digital Heritage International Congress (Digital Heritage), Oct. 28-Nov. 1 2013, Marseille, pp. 497 - 504.

Bynum P., 2010. Building Information Modeling in Support of Sustainable Design and Construction, University of Florida.

Dore, C., Murphy, M., 2012. Integration of Historic Building Information Modeling and 3D GIS for Recording and Managing Cultural Heritage Sites, 18th International Conference on Virtual Systems and Multimedia: "Virtual Systems in the Information Society", 2-5 September, 2012, Milan, Italy, pp. 369-376.

Eastman C., Teicholz P., Sacks R., Liston K., 2008. "BIM Handbook, A guide to Building Information Modeling for Owners, Managers, Designers, Engineers, and Contractors", John Wiley \& Sons, Hoboken, New Jersey

Fai S., Graham K., Duckworth T., Wood N., Attar R., 2011. Building Information Modeling and Heritage Documentation, CIPA 2011 Conference Proceedings: XXIIIrd International CIPA Symposium.

Foundation of the Wall and Ceiling Industry, 2009. Building Information Modeling: Understanding and Operating in a New Paradigm, Falls Church, http://www.awci.org/pdf/bim.pdf

Garagnani, S., Manfredini, A. M., 2013. Parametric Accuracy: Building Information Modeling Process Applied to the Cultural Heritage Preservation, 4th ISPRS International Workshop "3D-ARCH”, Trento, Italy

Hergunsel, M. F., 2011. Benefits of Building Information Modeling for Construction Managers and BIM-based scheduling, Worcester Polytechnic Institute.

Krygiel, E., Nies, B., 2008. Green BIM: Successful Sustainable Design with Building Information Modeling, 1st ed., Wiley, New York.

Maddigan, J. 2012. HCF National Heritage Summit, Canadian Association of Heritage Professionals.
Murphy, M., McGovern E., et al., 2009. "Historic building information modelling (HBIM). "Structural Survey Vol. 27 (Iss: 4, ): $311-327$.

Murphy M., McGovern E. \& Pavia, S. 2011. 'Historic Building Information Modeling - Adding Intelligence to

Laser and Image Based Surveys', 4th ISPRS International Workshop, 3D ARCH 2011: "3D Virtual Reconstruction and Visualization of Complex Architectures" Trento, Italy, 2-4 March 2011.

Murphy, M., Dore, C., 2012. Integration of Historic Building Information Modeling (HBIM) and 3D GIS for Recording and Managing Cultural Heritage Sites, 18th International Conference on Virtual Systems and Multimedia (VSMM): "Virtual Systems in the Information Society", 2-5 September 2012, Milan, Italy, pp. 369-376.

Oreni D., Brumana R., Della Torre S., Banfi F., Barazzetti L., Previtali M., 2014. "Survey turned into HBIM: the restoration and the work involved concerning the Basilica di Collemaggio after the earthquake (L'Aquila)", ISPRS Technical Commission V Symposium, 23-25 June 2014, Italy.

Popov, V., Mikalauskas, S., Migilinskas, D., Vainiunas, P., 2006. "Complex Usage of 4D Information Modeling Concept for Building Design, Estimation, Scheduling, and Determination of Effective Variant".

Saeed KIA, 2013. Review of Building Information Modeling (BIM) Software Packages Based on Assets Management, Amirkabir University of Technology, Department of Civil and Environmental Engineering, 27 March 2013.

Saygi, G., Remondino, F., 2013. Management of Architectural Heritage Information in BIM and GIS: State-ofthe-art and Future Perspectives. Int. Journal of Heritage in the Digital Era, Vol.2(4), pag. 695-714, DOI 10.1260/20474970.2.4.695. 